University of Wollongong

Research Online

Faculty of Engineering - Papers (Archive)

Faculty of Engineering and Information

Sciences

$1-1-2012$

\title{
Hydrogen-induced microstructure, texture and mechanical property evolutions in a high-pressure torsion processed zirconium alloy
}

Zhiyang Wang

University of Wollongong, zw603@uowmail.edu.au

Ulf Garbe

Australian Nuclear Science and Technology Organisation

Huijun Li

University of Wollongong, huijun@uow.edu.au

Andrew J. Studer

Australian Nuclear Science And Technology Organisation

Robert P. Harrison

Australian Nuclear Science And Technology Organisation

See next page for additional authors

Follow this and additional works at: https://ro.uow.edu.au/engpapers

Part of the Engineering Commons

https://ro.uow.edu.au/engpapers/5324

\section{Recommended Citation}

Wang, Zhiyang; Garbe, Ulf; Li, Huijun; Studer, Andrew J.; Harrison, Robert P.; Callaghan, Mark D.; Wang, Yanbo; and Liao, Xiaozhou: Hydrogen-induced microstructure, texture and mechanical property evolutions in a high-pressure torsion processed zirconium alloy 2012, 752-755.

https://ro.uow.edu.au/engpapers/5324 


\section{Authors}

Zhiyang Wang, Ulf Garbe, Huijun Li, Andrew J. Studer, Robert P. Harrison, Mark D. Callaghan, Yanbo Wang, and Xiaozhou Liao 


\title{
Hydrogen-induced microstructure, texture and mechanical property evolutions in a high-pressure torsion processed zirconium alloy
}

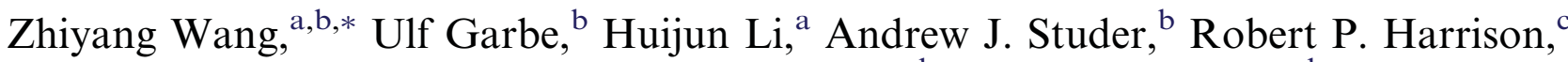 \\ Mark D. Callaghan, ${ }^{\mathrm{a}}$ Yanbo Wang ${ }^{\mathrm{d}}$ and Xiaozhou Liao ${ }^{\mathrm{d}}$ \\ ${ }^{a}$ Faculty of Engineering, University of Wollongong, Northfields Avenue, Wollongong, NSW 2522, Australia \\ ${ }^{\mathrm{b}}$ The Bragg Institute, Australian Nuclear Science and Technology Organisation, New Illawarra Road, Lucas Heights, \\ NSW 2234, Australia \\ ${ }^{\mathrm{c}}$ The Institute of Materials Engineering, Australian Nuclear Science and Technology Organisation, New Illawarra Road, \\ Lucas Heights, NSW 2234, Australia \\ ${ }^{\mathrm{d}}$ School of Aerospace, Mechanical and Mechatronic Engineering, The University of Sydney, NSW 2006, Australia
}

Received 18 May 2012; revised 20 July 2012; accepted 25 July 2012

Available online 31 July 2012

\begin{abstract}
The gaseous hydriding-induced evolutions of the microstructure, texture and mechanical properties of Zircaloy-4 processed by high-pressure torsion (HPT) were assessed. Much $\delta-\mathrm{ZrH}_{1.66}$ precipitation at $15 \mathrm{~atm}(21 \%)$ incurred significant hardening of vacuumannealed HPT samples, and pure $\varepsilon-\mathrm{ZrH}_{2}$ obtained at $20 \mathrm{~atm}$ showed a superior microhardness of $470 \mathrm{HV}_{0.3}$ and a low fracture toughness of $0.63 \mathrm{MPa} \mathrm{m}^{1 / 2}$. The $\delta$-hydrides presented strong (111) texture and followed the $(0001)_{\alpha-\mathrm{Zr}} / /\{111\}_{\delta \text {-ZrH1.66 }}$ orientation relationship with the $\alpha-Z r$ matrix. During hydriding, $\alpha-Z r$ recrystallization texture was developed from the initial deformation texture.

(c) 2012 Acta Materialia Inc. Published by Elsevier Ltd. All rights reserved.
\end{abstract}

Keywords: High-pressure torsion; Hydrogen embrittlement; Texture; Neutron diffraction; Zircaloy-4

The zirconium alloy Zircaloy-4 (Zr-4) is widely used as a key structural material in nuclear reactors due to its low neutron absorption, high ductility and stability $[1,2]$. One of the primary problems for Zr-4 components during service is the absorption of hydrogen and the resultant formation of brittle hydrides, which significantly degrades the ductility and fracture toughness of the material. Hydride precipitation in a zirconium alloy is a complicated process, influenced by multiple factors including grain size, texture and stress state of the material [3]. Considerable research efforts have been hitherto devoted to investigating the hydride precipitation behaviors in zirconium alloys under different thermomechanical status $[3,4]$.

Nanostructured Zr-4 material was recently successfully prepared [5] by high-pressure torsion (HPT), which is a severe deformation technique that refines the grain sizes of metallic materials down to the nanometer regime [6]. Although the strength of this nanocrystalline $\mathrm{Zr}-4$

\footnotetext{
* Corresponding author at: Faculty of Engineering, University of Wollongong, Northfields Avenue, Wollongong, NSW 2522, Australia. Tel.: +61 2 42214143; fax: +612 42213238; e-mail: zw603@uowmail. edu.au
}

material is improved, the comprehensive properties need to be evaluated before considering its practical applications in nuclear reactors, especially the resistance to hydride embrittlement. Our preliminary metallographic studies have indicated that the HPT samples exhibited the higher potential for the hydride precipitation compared with samples without HPT processing [7]. Further in-depth work concerning hydriding and its effects on structural and mechanical properties of HPT $\mathrm{Zr}-4$ are essential to enhance our understanding of the hydride formation behaviors in zirconium alloys with nanostructure and potential deformation texture.

In this work, HPT-processed $\mathrm{Zr}-4$ discs [5] were subjected to gaseous hydrogen charging at various hydrogen pressures. The hydriding processing-microstructureproperty relationship of the material was investigated. The texture evolutions of the HPT discs due to thermal effects during hydriding were also studied using neutron diffraction.

A commercial $\mathrm{Zr}-4$ material with a chemical composition (wt.\%) of $\mathrm{Zr}_{98.11} \mathrm{Sn}_{1.56} \mathrm{Fe}_{0.22} \mathrm{Cr}_{0.11}$ was used in this study. Unconstrained HPT processing on disc samples with a thickness of $0.8 \mathrm{~mm}$ and a diameter of $10 \mathrm{~mm}$ 
was conducted at room temperature under a pressure of 3.8 GPa. Previous detailed microstructural characterization of the HPT materials [5] revealed that the HPT samples exhibit a homogenous nanocrystalline structure with grain sizes of $\sim 100 \mathrm{~nm}$ after five revolutions of HPT processing. These HPT samples were gaseously hydrided in a vacuum furnace using high-purity hydrogen $(99.9 \%)$ at pressures of 10, 15 and $20 \mathrm{~atm}$. For hydriding, the samples were soaked at $450{ }^{\circ} \mathrm{C}$ for $15 \mathrm{~h}$ followed by furnace cooling to $25^{\circ} \mathrm{C}$ with a cooling rate of $\sim 2.2^{\circ} \mathrm{C} \mathrm{min}^{-1}$. Two HPT samples were vacuum-annealed at $450{ }^{\circ} \mathrm{C}$ for $15 \mathrm{~h}$ to separately track the structural evolution of the $\mathrm{Zr}-4$ matrix induced by the thermal effects during hydriding. One vacuum-annealed sample was further hydrided under 15 atm hydrogen pressure using the same hydriding procedure.

The microstructure of cross-sections of $\mathrm{Zr}-4$ samples was examined by mounting them in epoxy and polishing according to standard metallographic techniques. Samples were etched with a solution consisting of $10 \mathrm{ml} \mathrm{HF}$, $100 \mathrm{ml} \mathrm{HNO}_{3}$ and $100 \mathrm{ml}$ distilled water for $30 \mathrm{~s}$ and observed using a JEOL JSM-6490LA scanning electron microscope (SEM). The volume fractions of hydrides formed after hydriding were estimated based on the SEM micrographs using the software ImageJ. ${ }^{1}$ Phase identification was performed by a GBC MMA X-ray diffractometer (XRD) with $\mathrm{Cu} \mathrm{K} \alpha$ radiation $(\lambda=1.5418 \AA$ ). The Vickers microhardness was measured using a LECO $\mathrm{M}-400-\mathrm{H} 1$ microhardness tester at a load of $0.3 \mathrm{~kg}$. At least ten indents were taken for each sample. A nanoindentation test on the polished cross-section of the 20 atm hydrided HPT sample was performed using a Hysitron TI 900 TriboIndenter. The nanoindentation measurements were conducted on 24 different points of the sample using a loading-unloading test mode at a test force of $5 \mathrm{mN}$.

The bulk texture of samples was measured using neutrons at a wavelength of $2.41 \AA$ on Wombat, the highintensity powder diffractometer at the Australian Nuclear Science and Technology Organisation [8]. Diffraction patterns including a set of chosen diffraction peaks for the pole figure analysis were recorded with the samples mounted on an Eulerian cradle using a position sensitive area detector. For the pole figure measurements, samples were tilted $\left(\chi=0-90^{\circ}\right)$ and rotated $\left(\varphi=0-360^{\circ}\right)$ in equal-distance steps, typically on a $15 \times 5^{\circ}$ grid in a three-dimensional orientation sphere, while the $\omega$ angle was fixed at $27.6^{\circ}$. Diffraction data was analyzed to determine individual pole figures from the orientation distribution function (ODF) using the software packages 2DiffCalc [9] and MTEX [10].

Figure 1 shows the effect of hydrogen charging pressure on the cross-sectional microstructures, phases and microhardness of HPT discs. The common acicular or platelet-like hydrides were clearly visible on cross-sections of the 10 and $15 \mathrm{~atm}$ hydrided HPT discs. For the sample hydrided at $10 \mathrm{~atm}$, the hydride needles and nearly equiaxed $\alpha-\mathrm{Zr}$ grains were observed (Fig. 1a). At 15 atm, a high concentration of hydride platelets was formed (Fig. 1b). As the applied hydrogen pressure raised from 10 to $15 \mathrm{~atm}$, the hydride volume fraction significantly increased from $4 \%$ to $21 \%$ according to the image quantitative analysis of

\footnotetext{
${ }^{1}$ http://rsbweb.nih.gov/ij/
}
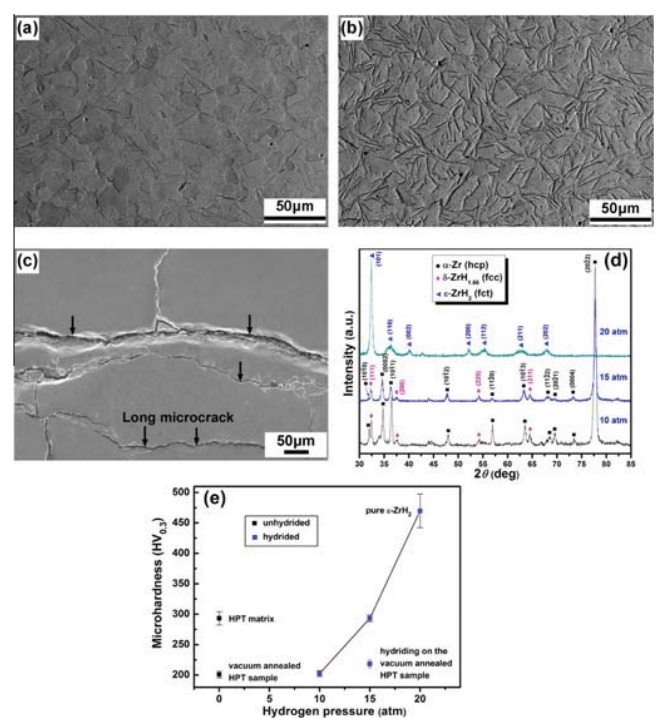

Figure 1. SEM micrographs showing typical microstructures on crosssections of hydrided HPT Zr-4 samples at hydrogen pressures of (a) $10 \mathrm{~atm}$, (b) $15 \mathrm{~atm}$ and (c) $20 \mathrm{~atm}$. (d) XRD patterns of the hydrided HPT samples [7] and (e) Vickers microhardness of the hydrided and unhydrided samples. The arrows in (c) indicate the presence of long microcracks. Error bars in the microhardness data (e) show one standard deviation.

the SEM micrographs (Fig. 1a and b) and, meanwhile, the average microhardness of the samples elevated from 203 to $292 \mathrm{HV}_{0.3}$ (Fig. 1e). Note that the as-received HPT sample possessed a superior average microhardness of $293 \mathrm{HV}_{0.3}$ (Fig. 1e) due to a significant grain refinement and generation of high dislocation density after HPT deformation $[6,11]$. As the hydrogen pressure increased to $20 \mathrm{~atm}$, the typical needle/platelet-shaped hydride morphology disappeared and long microcracks were present in the microstructure and a high average microhardness of $470 \mathrm{HV}_{0.3}$ was obtained (Fig. 1c and e). XRD was applied to study the constitution phases of the hydrided samples. For the 10 and 15 atm hydrided samples, the strong diffraction peaks of $\alpha-\mathrm{Zr}$ and $\delta-\mathrm{ZrH}_{1.66}$ were generally identified (Fig. 1d). In contrast, all strong XRD peaks in the $20 \mathrm{~atm}$ hydrided sample were indexed to correspond to $\varepsilon-\mathrm{ZrH}_{2}$, indicative of a complete transformation of $\mathrm{Zr}-4$ alloy to pure $\varepsilon-\mathrm{ZrH}_{2}$. The metastable $\zeta-\mathrm{Zr}_{2} \mathrm{H}$ phase [12] was not observed in the present hydriding condition. Combined with the SEM and microhardness results (Fig. 1), it was reasonable to conclude that the variation of hydrogen pressure resulted in the evolutions of the hydrided samples in terms of the hydride phase, morphology and the corresponding mechanical property.

The hydrogen solubility in $\mathrm{Zr}-4$ alloy $\left(C_{\mathrm{H}}\right)$ for the gaseous hydriding process can be estimated using Sievert's law [13]: $C_{\mathrm{H}}=k \cdot p_{\mathrm{H}_{2}}^{1 / 2}$, where $p_{\mathrm{H}_{2}}$ is the hydrogen partial pressure, and $k$ is the Sievert's constant. Thus, applying a higher hydrogen pressure will lead to a higher absorption of hydrogen during hydriding heating process and resultant greater supersaturation of hydrogen within the matrix lattice during cooling, favoring the hydride nucleation and subsequent nucleus growth. At the highest hydrogen pressure of $20 \mathrm{~atm}$, it is believed that excessive hydrogen absorption by the $\mathrm{Zr}-4$ alloy is achieved, promoting the formation of pure $\varepsilon-\mathrm{ZrH}_{2}$ phase (Fig. 1d). At a hydrogen pressure of $15 \mathrm{~atm}$, moderate 
hydrogen absorption is yielded, leading to the precipitation of $\delta$-hydride platelets with a high volume fraction of $21 \%$ (Fig. 1b). As the pressure decreased to $10 \mathrm{~atm}$, the absorbed hydrogen amount in $\mathrm{Zr}-4$ was limited, and the morphology of $\delta$-hydride evolved into the needle-shape with a low volume fraction of $4 \%$ (Fig. 1c). The interesting features found in the $10 \mathrm{~atm}$ sample are the equiaxed $\alpha-\mathrm{Zr}$ grains formation and significant microhardness degradation compared with the as-received sample (Fig. 1a and e). It was accordingly inferred that a low temperature recrystallization of the HPT $\mathrm{Zr}-4$ matrix occurred at $450^{\circ} \mathrm{C}$ during hydriding, as the typical recrystallization temperature range of conventional cold deformation $\mathrm{Zr}-4$ is between 470 and $650^{\circ} \mathrm{C}[14,15]$. The high stored energy in HPT deformation, as the driving force for recrystallization, could stimulate the occurrence of recrystallization at a low temperature. The operation of this softening mechanism caused the prominent decrease in microhardness of the HPT sample after hydriding at 10 atm (Fig. 1e). The comparable microhardness of the $15 \mathrm{~atm}$ sample to that of the HPT matrix (Fig. 1e) is a consequence of the combined effects of the precipitation hardening of the large concentration hydrides and the recrystallization softening of the matrix.

Figure $2 \mathrm{a}$ shows the cross-section microstructure of the HPT disc after vacuum annealing at $450{ }^{\circ} \mathrm{C}$ for $15 \mathrm{~h}$. The equiaxed $\alpha-\mathrm{Zr}$ grains were clearly present in this microstructure, suggesting the emergence of recrystallization after annealing, and hence a relatively low microhardness of $201 \mathrm{HV}_{0.3}$ was measured for the annealed sample (Fig. 1e). Compared with the vacuum-annealed HPT sample, no apparent microhardness increase is observed for the $10 \mathrm{~atm}$ hydrided sample with a very low fraction of hydrides, while significant hardening is induced by the precipitation of large amounts of hydrides in the hydrided HPT samples at 15 and $20 \mathrm{~atm}$ (Fig. 1e). The hydrides precipitation during cooling introduces local stresses (due to hydrides volume expansion) and dislocations $[16,17]$, contributing to the potential hardening effect of hydrides. The vacuum-annealed disc is further hydrided at 15 atm using the identical hydriding process for the HPT samples. In this instance, only few hydride platelets with an estimated volume fraction of $2 \%$ were observed on the cross-section (Fig. 2b) and a low microhardness of $218 \mathrm{HV}_{0.3}$ was measured (Fig. 1e). Compared with the HPT sample without prior annealing treatment, the recrystallized sample exhibited the enhanced resistance to hydride formation at hydriding pressure of $15 \mathrm{~atm}$. It is reported that dislocations are favorable sites for hydride nucleation, which can effectively accommodate the misfit strain associated with the hydride precipitation [18]. During the prior recrystallization annealing, the annihilation of dislocations in the
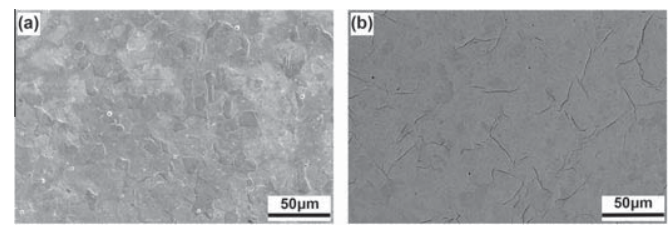

Figure 2. SEM images showing characteristic microstructures of the vacuum-annealed HPT sample before (a) and after (b) hydriding at a hydrogen pressure of $15 \mathrm{~atm}$.
HPT samples is initiated, inducing the lack of preferred nucleation sites for hydrides and resultant limited hydride formation after hydriding (Fig. 2b).

The attained pure $\varepsilon-\mathrm{ZrH}_{2}$ at $20 \mathrm{~atm}$ displayed an exceptionally high average microhardness of $470 \mathrm{HV}_{0.3}$. In this case, the microhardness indentation with a welldefined microcrack morphology was observed (Fig. 3a). Such indentation crack development is driven by the residual stress field in the material, and the crack extending length is related to the material crack propagation resistance [19]. The fracture toughness $K_{\mathrm{IC}}$ of $\varepsilon$-hydride can be estimated following the indentation microfracture method and using the expression $[19,20]$ :

$K_{\mathrm{IC}}=\xi\left(\frac{E}{H}\right)^{1 / 2} \frac{P}{c^{3 / 2}}$

where $E$ is the Young's modulus, and $H$ is the hardness, $P$ is the indentation load (in the present Vickers microhardness test the applied load $P$ is $0.3 \mathrm{~kg}$ ), $c$ is the length of the radial cracks and $\xi$ is a constant related to the geometry of the indenter (for Vickers indenters $\xi$ is 0.016 ). The crack length $c$ was evaluated as $\sim 43.2 \mu \mathrm{m}$ from the SEM micrograph showing the microhardness impression and crack morphology (Fig. 3a). The $E$ and $H$ of the $\varepsilon-\mathrm{ZrH}_{2}$ material were determined by applying nanoindentation tests on various positions of its polished section, as shown in Figure 3b. During each nanoindentation measurement, an indentation loaddepth curve was recorded (a representative load-depth curve is shown in the inset in Fig. 3b), from which the corresponding $E$ and $H$ values could be determined. The average values of $E$ and $H$ for $\varepsilon-\mathrm{ZrH}_{2}$ were $78.5 \mathrm{GPa}$ and $5.4 \mathrm{GPa}$, respectively. Adopting the above experimental results, the fracture toughness $K_{\mathrm{IC}}$ of the $\varepsilon$ $\mathrm{ZrH}_{2}$ was estimated to be $0.63 \mathrm{MPa} \mathrm{m}^{1 / 2}$.

Figure $4 \mathrm{a}$ and $\mathrm{b}$ shows the texture changes of the starting HPT disc before and after vacuum annealing. The HPT disc only presented a strong (0002) basal texture having the pole maxima of 3.9 multiples of the random distribution (mrd) along the axial direction (AD) of the disc (Fig. 4a). With the emergence of significant recrystallization after annealing (Fig. 2a), the (0 0002$)$ basal texture was weakened in comparison to the initial deformation texture and meanwhile, a prismatic $(10 \overline{1} 0)$ texture was developed (Fig. 4b). The basal pole figure displayed a broad pole maximum ( $3 \mathrm{mrd}$ ) parallel to the tangential (TD) and radial (RD) plane and also a retained weak pole along AD. The (1010) pole figure showed a clear maximum along AD. Furthermore, it reveals that the development of the $(10 \overline{1} 0)$ component parallel to $\mathrm{AD}$ is at the expense of the $(0002)$ deformation component parallel
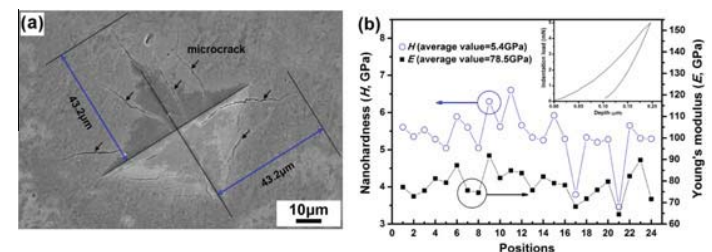

Figure 3. (a) SEM image of a Vickers microhardness indentation and (b) Young's modulus and nanohardness of the 20 atm hydrided HPT sample (pure $\varepsilon-\mathrm{ZrH}_{2}$ ) measured by nanoindentation tests; the inset shows a representative indentation load-depth curve. 
to AD, manifesting that the $[0002]$ grain orientations rotate by $\sim 90^{\circ}$ around a $\langle 1010\rangle$ axis during recrystallization. This characteristic rotation has been previously reported in $\mathrm{Ti}$ and $\mathrm{Zr}$ during the recrystallization process [21]. Further investigation is required to understand the origin of this rotation of the [0002] grain orientations in HPT $\mathrm{Zr}-4$ after recrystallization. Figure $4 \mathrm{c}$ displays a representative neutron diffraction pattern of the $15 \mathrm{~atm}$ hydrided HPT sample, with the background fitted using the 2DiffCalc routine [9]. Diffraction peaks for texture analysis were indexed, including (0002), (1010) and (1011) peaks of $\alpha-\mathrm{Zr}$ and (111) peak of $\delta-\mathrm{ZrH}_{1.66}$ (Fig. 4c). As the hydride peak intensity is low in neutron diffraction essentially due to the small coherent neutron scattering cross section of hydrogen, only the strongest (111) peak of $\delta-\mathrm{ZrH}_{1.66}$ was unambiguously identified in the $15 \mathrm{~atm}$ hydrided HPT sample. The calculated

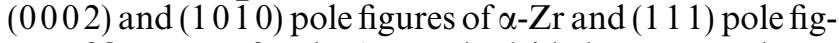
ure of $\delta-\mathrm{ZrH}_{1.66}$ for the $15 \mathrm{~atm}$ hydrided HPT sample are demonstrated in Figure $4 \mathrm{~d}$ and e. Through pole figures

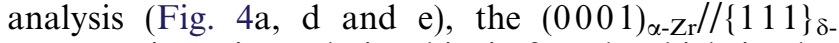
$\mathrm{ZrH1} 1.66$ orientation relationship is found, which is also supported by the previous studies using electron backscattered diffraction (EBSD) [1,2] and Synchrotron [22] techniques. This hydride--matrix orientation correlation essentially results from the preferred lattice matching of the involved $\left(\begin{array}{llll}0 & 0 & 0 & 1\end{array}\right)_{\alpha-\mathrm{Zr}}$ and $\left\{\begin{array}{lll}1 & 1 & 1\end{array}\right\}_{\delta-\mathrm{ZrH} 1.66}$ atomic planes [16]. Besides, the developed recrystallization basal and prismatic textures of $\alpha-\mathrm{Zr}$ under vacuum and $15 \mathrm{~atm}$ hydrogen atmospheres are similar (Fig. 4b and d) in dominant shape and intensity. The main differences are that

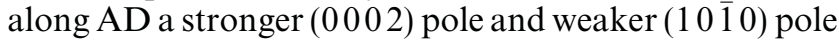
of $\alpha-\mathrm{Zr}$ are observed for the 15 atm hydrided HPT sample than those for the vacuum-annealed sample. It is considered that the hydrogen solute atoms dissolved in $\mathrm{Zr}-4$ lattice during hydriding at $15 \mathrm{~atm}$ hydrogen may retard the recrystallization to some extent [23] and hence preserving more [0 0002 ] grain orientations along AD (Fig. 4d). Furthermore, hydrogen in solid solution plays an inhibiting role in the static recovery by limiting climb or annihilation of the dislocations, which is linked to the recrystallization phenomenon [24].

In summary, the microstructural, textural and mechanical properties of the gaseously hydrided HPT-

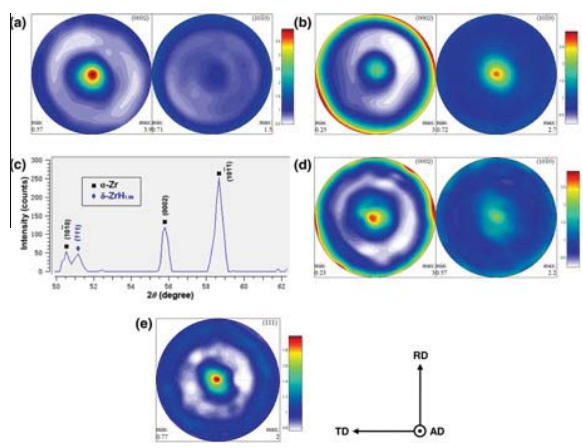

Figure 4. Basal (0002) and prismatic (1010) pole figures of the $\alpha-\mathrm{Zr}$ phase determined by neutron diffraction for the (a) starting HPT Zr-4 disc, (b) vacuum-annealed HPT sample and (d) HPT sample hydrided at a hydrogen pressure of $15 \mathrm{~atm}$. (c) A neutron diffraction pattern obtained from the $15 \mathrm{~atm}$ hydrided HPT sample. (e) (11 1) pole figure of the $\delta-\mathrm{ZrH}_{1.66}$ precipitated in the 15 atm hydrided HPT sample. The sample reference frame for direct pole figures is shown on the right of (e). processed $\mathrm{Zr}-4$ discs at different hydrogen pressures were investigated. The $\delta-\mathrm{ZrH}_{1.66}$ hydrides formed at $10 \mathrm{~atm}$ hydrogen pressure showed the needle-like morphology while thick $\delta$-hydride platelets developed at $15 \mathrm{~atm}$. A large volume fraction of $\delta$-hydrides $(21 \%)$ precipitated at $15 \mathrm{~atm}$, leading to the prominent enhancement in microhardness of the vacuum-annealed HPT sample. At $20 \mathrm{~atm}$, pure $\varepsilon-\mathrm{ZrH}_{2}$ was attained, possessing a high microhardness of $470 \mathrm{HV}_{03}$ and an estimated fracture toughness of $0.63 \mathrm{MPa} \mathrm{m}^{1 / 2}$. The HPT disc presents a strong (0002) basal texture along AD and due to the

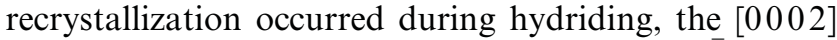
grain orientations rotated by $\sim 90^{\circ}$ around a $\langle 10 \overline{1} 0\rangle$ axis, leading to the developments of $(0002)$ pole maxima perpendicular to AD and the (1010) component along AD. The $\delta$-hydrides displayed strong (111) textures along AD and followed the $(00001)_{\alpha-Z r} / /\left\{\begin{array}{lll}1 & 1 & 1\end{array}\right\}_{\delta \text {-ZrH1.66 }}$ orientation relationship with matrix.

Financial support from the China Scholarship Council (CSC) and the Australian Nuclear Science and Technology Organisation (ANSTO) are appreciated.

[1] N.A.P. Kiran Kumar, J.A. Szpunar, Z. He, J. Nucl. Mater. 403 (2010) 101.

[2] W. Qin, N.A.P. Kiran Kumar, J.A. Szpunar, J. Kozinski, Acta Mater. 59 (2011) 7010.

[3] J.R. Santisteban, M.A. Vicente-Alvarez, P. Vizcaíno, A.D. Banchik, J.D. Almer, Acta Mater. 58 (2010) 6609.

[4] M. Veleva, S. Arsene, M.-C. Record, J. Bechade, J.B. Bai, Metall. Mater. Trans. A 34 (2003) 567.

[5] Y.B. Wang, M. Louie, Y. Cao, X.Z. Liao, H.J. Li, S.P. Ringer, Y.T. Zhu, Scripta Mater. 62 (2010) 214.

[6] A.P. Zhilyaev, T.G. Langdon, Prog. Mater. Sci. 53 (2008) 893.

[7] Z.Y. Wang, H.J. Li, U. Garbe, M.D. Callaghan, Y.B. Wang, X.Z. Liao, Mater. Lett. 68 (2012) 310.

[8] A.J. Studer, M.E. Hagen, T.J. Noakes, Physica B 385 (2006) 1013

[9] U. Garbe, J. Appl. Crystallogr. 42 (2009) 730.

[10] R. Hielscher, H. Schaeben, J. Appl. Crystallogr. 41 (2008) 1024.

[11] A.P. Zhilyaev, S. Lee, G.V. Nurislamova, R.Z. Valiev, T.G. Langdon, Scripta Mater. 44 (2001) 2753.

[12] Z. Zhao, J.P. Morniroli, A. Legris, A. Ambard, Y. Khin, L. Legras, M. Blat-Yrieix, J. Microsc. 232 (2008) 410.

[13] J.H. Huang, S.P. Huang, Mater. Sci. Eng. A 161 (1993) 247.

[14] L. Saintoyant, L. Legras, Y. Bréchet, Scripta Mater. 64 (2011) 418

[15] V.D. Hiwarkar, S.K. Sahoo, I. Samajdar, A. Satpathy, K.V.M. Krishna, G.K. Dey, D. Srivastav, R. Tewari, S. Banarjee, J. Nucl. Mater. 412 (2011) 287.

[16] G.J.C. Carpenter, J. Nucl. Mater. 48 (1973) 264.

[17] G.J.C. Carpenter, J.F. Watters, R.W. Gilbert, J. Nucl. Mater. 48 (1973) 267.

[18] V. Perovic, G.C. Weatherly, J. Nucl. Mater. 126(1984) 160.

[19] N. Cuadrado, D. Casellas, M. Anglada, E. JiménezPiqué, Scripta Mater. 66 (2012) 670.

[20] J.J. Xu, S.Q. Shi, J. Nucl. Mater. 327 (2004) 165.

[21] K. Lücke, R. Rixen, Metall. Mater. Trans. B 1 (1970) 259.

[22] M.A. Vicente Alvarez, J.R. Santisteban, G. Domizzi, J. Almer, Acta Mater. 59 (2011) 2210.

[23] F.J. Humphreys, M. Hatherly, Recrystallization and Related Annealing Phenomena, second ed., Elsevier, Oxford, 2004

[24] N. Rupa, M. Clavel, P. Bouffioux, C. Domain, A. Legris, in: Zirconium in the Nuclear Industry: 13th International Symposium, ASTM STP 1423, 2002, p. 811. 